\title{
INFLUÊNCIA DO POLIMORFISMO I/D DO GENE DA ECA NA HPE DE JOVENS NORMOTENSOS
}

\author{
INFLUENCE OF I/D POLYMORPHISM OF THE ACE GENE ON PEH IN \\ NORMOTENSIVE YOUNG MEN
}

Artigo Original

Original ARTICLE

Artículo Original

\author{
INFLUENCIA DEL POLIMORFISMO I/D DEL GEN DE LA ECA EN LA HPE \\ DE JÓVENES NORMOTENSOS
}

\author{
Manuella de Oliveira Fernandes' \\ (Educadora Física) \\ Luan Morais Azevêdo \\ (Educador Físico) \\ Silvio Santana Dolabella' \\ (Farmacêutico) \\ Emerson Pardono' \\ (Educador Físico)
}

1. Universidade Federal de Sergipe (UFS), São Cristóvão, SE, Brasil.

\section{Correspondência:}

Departamento de Educação Física - Programa de Pós-Graduação em Educação Física da Universidade Federal de Sergipe.

Av. Marechal Rondon, $s / n$, Jardim Rosa Elze, São Cristóvão, SE, Brasil. 49100-000.pardono@ufs.br

\section{RESUMO}

Introdução: A hipotensão pós-exercício (HPE) é considerada uma estratégia não farmacológica adotada para redução da pressão arterial (PA). Ademais, sabe-se que a presença de alguns polimorfismos genéticos influencia a resposta pressórica, como o l/D do gene da enzima conversora da angiotensina (ECA). Objetivo: Analisar a influência do polimorfismo I/D da ECA sobre a HPE após três diferentes intensidades de exercício em jovens normotensos e fisicamente ativos. Métodos: Vinte e seis jovens saudáveis $(\mathrm{DD}=11 ; \mathrm{ID} / \|=15)$ realizaram uma sessão máxima de 1.600 metros, na pista de atletismo e outras três sessões experimentais (Sessão Moderada: 6\% abaixo do limiar anaeróbio, Sessão Intensa: 6\% acima do limiar anaeróbio e Sessão de Controle), com aferições prévias da PA, por 20 minutos e posteriores ao exercício por 60 minutos. Resultados: Observou-se que o exercício moderado ocasionou HPE independentemente do grupo genotípico, sendo mais evidente para a pressão arterial sistólica nos momentos 45 minutos e 60 minutos $(p \leq 0,05)$. Verificou-se também que a característica gênica exerceu influência sobre a área abaixo da curva pressórica $(p \leq 0,005)$ sobre a pressão arterial diastólica, formada 1 hora após o exercício. Conclusão: Conclui-se que o exercício moderado ocasiona HPE em jovens normotensos e fisicamente ativos, independentemente do polimorfismo I/D no gene da ECA, sendo que esse polimorfismo exerce influência sobre a hipotensão diastólica, e os indivíduos portadores do alelo I apresentam maior decaimento da PA diastólica (PAD).

Palavras-chave: exercício; hipotensão pós-exercício, enzima conversora da angiotensina, pressão arterial.

\begin{abstract}
Introduction: The post-exercise hypotension (PEH) is considered a non-pharmacological strategy adopted for lowering blood pressure (BP). Moreover, it is known that the presence of some genetic polymorphisms, such as the I/D of the angiotensin converting enzyme (ACE) gene, can influence the blood pressure response. Objective: Analyze the influence of the ACE I/D polymorphism on PEH after three different exercise intensities in normotensive and physically active young people. Methods: Twenty-six healthy young men ( $D D=11 ; I D / I=15)$ performed a maximal 1600 meters running session in a athletics track and another three experimental sessions (Moderate Session: $6 \%$ below the anaerobic threshold, Intense Session: 6\% above the anaerobic threshold, and a Control Session) with previous measurements of BP for 20 minutes and after the exercise for 60 minutes. Results: It was observed that moderate exercise has brought on $P E H$, regardless of genotype group, being more evident for systolic blood pressure at 45 minutes and 60 minutes $(p \leq 0.05)$. It was also found that the genic characteristics has influence on the area under the pressure curve $(p \leq 0.005)$ for the diastolic blood pressure, formed 1 hour after exercise. Conclusion: It is concluded that moderate exercise causes PEH in normotensive and physically active young men, regardless of I/D polymorphism in the ACE gene, that this polymorphism influences the diastolic blood pressure, and that subjects with the I allele have a greater drop in diastolic BP (DBP).
\end{abstract}

Keywords: exercise, post-exercise hypotension, angiotensin converting enzyme, arterial pressure.

\section{RESUMEN}

Introducción: La hipotensión post-ejercicio (HPE) es considerada una estrategia no farmacológica aprobada para bajar la presión arterial (PA). Además, se sabe que la presencia de determinados polimorfismos genéticos, tales como el polimorfismo I/D del gen de la enzima convertidora de angiotensina (ECA), influyen en la respuesta de la presión. Objetivo: Analizar la influencia del polimorfismo I/D del gen de la ECA en la HPE después de tres intensidades diferentes de ejercicio en los jóvenes normotensos y fisicamente activos. Métodos: Veintiséis jóvenes sanos $(D D=11 ; I D / I I=15)$ realizaron una sesión máxima de 1.600 metros en pista de atletismo y tres sesiones experimentales (Sesión Moderada: 6\% por debajo del umbral anaeróbico, Sesión Intensa: 6\% por encima del umbral anaeróbico y una Sesión de Control), con mediciones anteriores de PA durante 20 minutos y después del ejercicio, durante 60 minutos. Resultados: Se observó que el ejercicio moderado ha producido HPE independientemente del grupo de genotipo, siendo más evidente para la presión arterial sistólica en 45 minutos y 60 minutos $(p \leq 0,05)$. 
También se encontró que la característica génica ejerce influencia en el área bajo la curva de presión $(p \leq 0,005)$ para la presión arterial diastólica, formada 1 hora después del ejercicio. Conclusión: Se concluye que el ejercicio moderado provoca HPE en jóvenes normotensos y físicamente activos, independientemente del polimorfismo I/D del gen de la ECA, y que este polimorfismo tiene influencia en la presión arterial diastólica y los portadores del alelo I presentan mayor deterioro PA diastólica (PAD).

Palabras clave: ejercicio; hipotensión post-ejercicio, enzima convertidora de angiotensina, presión arterial.

\section{INTRODUÇÃO}

A prática regular de exercício físico é uma das estratégias, não farmacológicas, recomendadas pelos profissionais da área de saúde para a redução da pressão arterial (PA) ${ }^{1}$, sendo que tanto o exercício realizado cronicamente como de maneira aguda proporcionam tais benefícios pressóricos. Segundo Whelton et al. ${ }^{2}$, reduções de 3 e $5 \mathrm{mmHg}$ da PA podem reduzir o risco de infarto agudo do miocárdio de 8 a 14\%, enquanto a doença da artéria coronária e mortalidade geral podem reduzir de 5 a 9\%, e de 4 a 7\%, respectivamente.

A resposta crônica, ou adaptação, ocorre a partir de um treinamento sistematizado, sendo reportado que o exercício aeróbico é um dos mais eficazes ${ }^{1,3}$, embora em estudo recente ${ }^{4}$ também tenha sido demonstrado a boa eficácia do exercício resistido no que concerne ao controle da PA em idosas hipertensas. Já a resposta aguda ocorre em minutos ou horas subsequentes à prática do exercício, sendo conhecida por hipotensão pós-exercício (HPE)3. A HPE é caracterizada pela redução da PA para valores abaixo daqueles apresentados no pré-exercício ${ }^{5,6}$, podendo ser influenciada tanto por fatores ambientais, quanto por fatores étnicos e genéticos ${ }^{7,8}$.

O fator genético exerce notória influência sobre a PA, sendo reportado que de 30 a 40\% da propensão à hipertensão arterial sistêmica (HAS) refere-se à herança gênica de cada indivíduo9 ${ }^{9}$ As mutações gênicas existentes no sistema renina-angiotensina-aldosterona (SRAA) podem influenciar a regulação da PA de repouso, na resposta hipotensora dos inibidores da enzima conversora da angiotensina (ECA $)^{10} \mathrm{e}$ também na HPE7. Uma destas mutações refere-se ao polimorfismo de inserção/deleção do gene da ECA. Esse polimorfismo é caracterizado pela presença (inserção, alelo I) ou ausência (deleção, alelo D) de 287 pares de bases nitrogenadas no íntron 16 do braço longo do cromossomo 17, havendo relatos de que indivíduos carreadores do alelo I possuem menores concentrações séricas da ECA, quando comparado aos que possuem o alelo $D^{11}$, favorecendo à maior biodisponibilidade de substâncias vasoativas dilatadoras.

De maneira geral, poucos estudos analisaram a influência de mutações gênicas sobre a HPE $4,8,12,13$, sendo que destes apenas um foi conduzido em população jovem e normotensa ${ }^{8}$. A nossa hipótese é que indivíduos carreadores do alelo I para a mutação I/D no gene da ECA apresentem HPE de maior magnitude. Ademais, a investigação de populações jovens e saudáveis apresenta grande relevância aos estudos genéticos, uma vez que estes foram menos expostos aos fatores ambientais, aos processos endoteliais deletérios relacionadas ao envelhecimento e às fisiopatologias em geral, como a HAS${ }^{8}$.

Tendo em vista o exposto, o presente estudo objetivou investigar a influência do polimorfismo I/D do gene da ECA sobre a HPE após diferentes intensidades de corrida realizadas por indivíduos jovens, saudáveis e normotensos.

\section{MATERIAL E MÉTODOS}

O presente estudo foi aprovado pelo Comitê de Ética e Pesquisa local (No 12612813.2.0000.5546), no qual participaram voluntariamente
26 indivíduos normotensos do sexo masculino (DD: 23,6 $\pm 3,8$ anos; 70,5 $\pm 6,0$ kg; 173,7 $\pm 3,7 \mathrm{~cm}$; ID/II: 23,1 $\pm 2,8$ anos; 74,2 $\pm 7,6$ kg; 173,9 $\pm 5,5$ $\mathrm{cm}$ ) e fisicamente ativos, após assinarem um Termo de Consentimento Livre e Esclarecido.

Foram excluídos da pesquisa os indivíduos que possuíam alterações endócrinas, cardiovasculares, ortopédicas ou neurológicas, bem como tabagistas, usuários de recursos ergogênicos ou de fármacos que pudessem alterar a cinética da PA tanto no repouso, quanto no exercício. Todos os voluntários foram orientados a não praticar exercício físico intenso, ingestão de álcool e/ou cafeína, se alimentar normalmente e repetir o mesmo cardápio alimentar em todos os dias de coleta, além de manter o padrão de sono nas 48 horas que antecederam as sessões.

Os voluntários foram submetidos a quatro testes de corrida no período máximo de 15 dias. Tais testes foram realizados em dias distintos, no mesmo período do dia (matutino ou vespertino) e de forma randomizada, tendo como intervalo 72 horas entre as sessões de exercício. Na semana que antecedeu aos testes foi realizada uma familiarização com todos os sujeitos, bem como a coleta do material biológico para posterior análise.

A primeira sessão realizada foi o teste máximo de 1.600 metros (T1600), para que fosse identificado o limiar anaeróbio a partir da equação indireta proposta por Sotero et al. ${ }^{14}$. Posteriormente ao cálculo do limiar, realizaram-se os demais testes em ordem randomizada, sendo: $6 \%$ abaixo do limiar (MOD); 6\% acima do limiar (INT), ambos consistiram em uma corrida em uma pista de atletismo com volume de 20 minutos; e uma sessão controle sem exercício (SC).

Todos os testes foram compostos por um período pré-teste no qual os voluntários foram encaminhados a uma sala de repouso, onde permaneceram sentados durante 20 minutos, com aferição da PA sistólica (PAS) e da PA diastólica (PAD) a cada 5 minutos a partir da utilização de um aparelho automático devidamente validado ${ }^{15}$ (BP 3AC1-1, Microlife Inc., China). Nesta mesma sala climatizada foi realizado o período pós-teste, no qual, após o término das sessões experimentais foi novamente aferida a PA durante 60 minutos, registrando-se seus valores a cada 15 minutos.

Antes dos testes, os voluntários se deslocaram para a pista de atletismo e realizaram um aquecimento prévio de 5 minutos, com exceção da SC. Este aquecimento foi constituído por um breve alongamento, realizado de forma livre para as musculaturas solicitadas no teste e por uma corrida de baixa intensidade ao longo da pista.

Células da mucosa oral dos participantes foram coletadas com swab estéril e o material obtido submetido à extração do DNA genômico através do Axyprep ${ }^{T M}$ Multisource Genomic DNA Miniprep Kit (Axygen Scientific - USA), seguindo as orientações do fabricante. O DNA obtido foi quantificado, sendo posteriormente realizada a ampliação do fragmento de DNA contendo o sitio polimórfico de I/D no gene da ECA por meio da reação em cadeia da polimerase (PCR), utilizando a sequência de primers. Estes primers são utilizados a fim de amplificar a sequência aproximada de 190 pares de base (pb) para o genótipo DD e de 490pb para o genótipo II. 
A PCR foi realizada em um volume final de $25 \mu$, seguindo o seguinte protocolo: 12,5 $\mu$ ldo Master Mix, 5,5 $\mu$ ldo DNA , 4,5 $\mu$ lágua deionizada ultra-pura e uma mistura de indicadores direto e reverso totalizando $1 \mu$ de cada primers para cada amostra. Após o preparo, a reação foi colocada em um termociclador, alternando-se entre as temperaturas de 95,55 e $75^{\circ} \mathrm{C}$, respeitando-se: 5 minutos a $95^{\circ} \mathrm{C}$, 32 ciclos consistidos de 30 segundos a $95^{\circ} \mathrm{C}, 30$ segundos a $55^{\circ} \mathrm{C}$ e 30 segundos a $72^{\circ} \mathrm{C} ; 10$ minutos a $72^{\circ}$; e manutenção da temperatura em $10^{\circ} \mathrm{C}$ até a reação ser retirada do termociclador, segundo protocolo proposto por Leite ${ }^{16}$. Este protocolo foi adotado com o intuito de promover, respectivamente, a desnaturação do DNA (separação das fitas devido ao rompimento das pontes de hidrogênio), o anelamento dos indicadores às fitas simples de DNA e a incorporação dos dNTPs às novas fitas de DNA.

Os produtos da PCR foram separados em 1\% de gel de argarose,

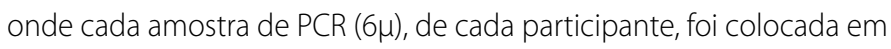
um poço formado no gel por um pente especifico, utilizando os marcadores com 490pb e 190bp, sendo que no primeiro poço foi aplicado $10 \mu l$ de tampão de carregamento (peso molecular) e $2 \mu l$ do corante Blue Green. As amostras correram por um período de 1h40min em 80V. Os produtos obtidos após esse período foram separados e corados por brometo de edítio (40 min), feito isso, realizou-se eletroforese a 100V, seguida da leitura dos fragmentos obtidos sob luz ultravioleta. As amostras foram classificadas em um dos três possíveis genótipos para o polimorfismo da ECA, dois homozigotos (DD e II) e um heterozigoto (ID), a partir dos procedimentos anteriormente descritos.

A identificação dos genótipos foi realizada visualizando a presença dos alelos " $D$ " $e$ "I", sendo que a presença de apenas um fragmento de $190 \mathrm{pb}$ caracteriza o genótipo DD e a presença de apenas um fragmento de 490pb caracteriza o genótipo Il. Adicionalmente, os heterozigotos ID foram identificados pela presença de ambos os fragmentos.

Para aumentar a especificidade da genotipagem, realizou-se uma PCR confirmatória para todas as amostras portadoras do genótipo $\mathrm{DD}$, utilizando um par de indicadores específicos para a inserção, ou seja, amplificadores do alelo 17,18. Desse modo, utilizou-se: Forward 5: TGG GAC CAC AGC GCC CGC CAC TAC 3'; Reverse 5: TCG CCA GCC CTA CCA TGC CCA TAA 3'.

\section{Analise estatística}

Os dados foram apresentados em média \pm desvio padrão (DP). Analise exploratória foi realizada para verificar se os dados seguiam uma distribuição normal pelo teste de Kolmogorov-Smirnov e a homogeneidade de variância da amostra entre os grupos foi avaliada através do teste de Levene. Análise de variância para medidas repetidas com comparação múltipla entre pares de Bonferroni foi aplicada intra-grupos para avaliação da HPE. A área abaixo da curva foi obtida pelo método trapezoide para investigar a magnitude de decaimento da PA após as sessões, sendo aplicado o teste two way ANOVA, com post hoc de Tukey (entre os testes), para analisar a influência dos genótipos, dos protocolos, bem como da interação destes entre estas áreas. O nível de significância adotado no presente estudo foi de $5 \%(p \leq 0,05)$ e o pacote estatístico SPSS versão 19.0 foi utilizado para a realização das análises estatísticas.

\section{RESULTADOS}

Visto que apenas quatro indivíduos possuíam genótipo II, optou-se pela união dos genótipos II e ID a fim de proporcionar adequada comparação entre os grupos genotípicos, procedimento também utilizado anteriormente por Pescatello et al.12 e Santana et al.13. As frequências genotípica e alélica dos dois grupos apresentaram um maior percentil do grupo genotípico DD (42,3\%) e alélica D (63,5\%).
Ao analisar a PAS pôde-se verificar que a SC não apresentou HPE em ambos os grupos genotípicos, resultado já esperado visto que os indivíduos permaneceram em repouso. Diferentemente, o teste MOD resultou em HPE nos momentos Rec45 e Rec60 para os dois grupos genotípicos $(p \leq 0,05)$. Entretanto, ao analisar o teste INT, observou-se diferença apenas entre os momentos Rec60 e $\operatorname{Rec} 15(p \leq 0,05)$ para o grupo carregador do alelo "I" (tabela 1).

Ao se investigar a magnitude do decaimento da PAS pós-exercício pela área abaixo da curva (AAC) pressórica, não foram evidenciadas influências significativas das características genéticas e tampouco da interação destas com as sessões experimentais. Contudo, houve diferença entre as AACs após as sessões SC e MOD (tabela 2 e figura 1), ou seja, quanto maior a AAC menor efeito hipotensor.

Os valores da PAD, para cada momento durante as três sessões experimentais, estão apresentados na tabela 3, sendo que na SC não ocorreu HPE. Fato interessante foi evidenciado após a sessão MOD do grupo DD, onde no momento Rec15 houve aumento da PAD $(p \leq 0,05)$.

Apenas alguns momentos evidenciaram HPE $(p \leq 0,05)$ para a PAD após a sessão MOD, sendo verificada no Rec30 para o grupo DD e no Rec60 para o grupo ID/II ( $p \leq 0,05)$. Com relação aos momentos pós-exercício da sessão INT, nenhum deles apresentaram HPE diastólica (tabela 3).

Tabela 1. Valores absolutos de PAS (em mmHg) durante as três sessões experimentais de cada grupo genotípico, para a análise de HPE intra-grupos genotípicos.

\begin{tabular}{c|c|c|c|c|c|c}
\hline \multirow{2}{*}{ Testes } & \multirow{2}{*}{ Grupos } & \multirow{2}{*}{$\begin{array}{c}\text { Repouso } \\
\text { Pré }\end{array}$} & & \multicolumn{4}{|c}{ Pós-exercício } \\
\cline { 4 - 7 } & & & $\operatorname{Rec} 15$ & $\operatorname{Rec} 30$ & $\operatorname{Rec} 45$ & $\operatorname{Rec} 60$ \\
\hline \multirow{2}{*}{$S C$} & $\mathrm{DD}$ & $123,8 \pm 12,3$ & $122,5 \pm 13,8$ & $123,3 \pm 12,1$ & $125,6 \pm 12,9$ & $122,5 \pm 13,4$ \\
\cline { 4 - 7 } & $\mathrm{ID} / \|$ & $122,2 \pm 0,8$ & $119,7 \pm 11,7$ & $121,7 \pm 11,5$ & $122,7 \pm 10,3$ & $122,2 \pm 12,2$ \\
\hline \multirow{2}{*}{ MOD } & $\mathrm{DD}$ & $123,6 \pm 1,7$ & $118,5 \pm 12,6$ & $115,2 \pm 9,5$ & $114,0^{*} \pm 9,6$ & $111,6^{*} \pm 7,1$ \\
\cline { 4 - 7 } & $\mathrm{ID} / \|$ & $123,2 \pm 2,6$ & $114,7 \pm 16,4$ & $115,0 \pm 11,4$ & $111,8^{*} \pm 9,5$ & $112,1^{*} \pm 8,8$ \\
\hline \multirow{2}{*}{ INT } & $\mathrm{DD}$ & $123,6 \pm 2,0$ & $119,4 \pm 15,7$ & $118,8 \pm 10,6$ & $116,9 \pm 10,6$ & $121,5 \pm 6,4$ \\
\cline { 4 - 7 } & $\mathrm{ID} / \|$ & $122,8 \pm 1,5$ & $121,0 \pm 14,3$ & $120,1 \pm 10,0$ & $115,6 \pm 10,8$ & $116,9^{* *} \pm 9,1$ \\
\hline
\end{tabular}

* $p \leq 0,05$ em relação ao repouso pré-exercício; ** $p \leq 0,05$ em relação ao Rec 15 . Rec: recuperação pós exercício

Tabela 2. Influência das características genotípicas, das sessões experimentais e da interação destas sobre a AAC da PAS.

\begin{tabular}{c|c|c}
\hline Variáveis & Valor de $\mathbf{F}$ & Significância \\
\hline Genótipos & 0,977 & 0,326 \\
\hline Sessões experimentais & 3,274 & 0,044 \\
\hline Genótipos x sessões experimentais & 0,180 & 0,836 \\
\hline
\end{tabular}

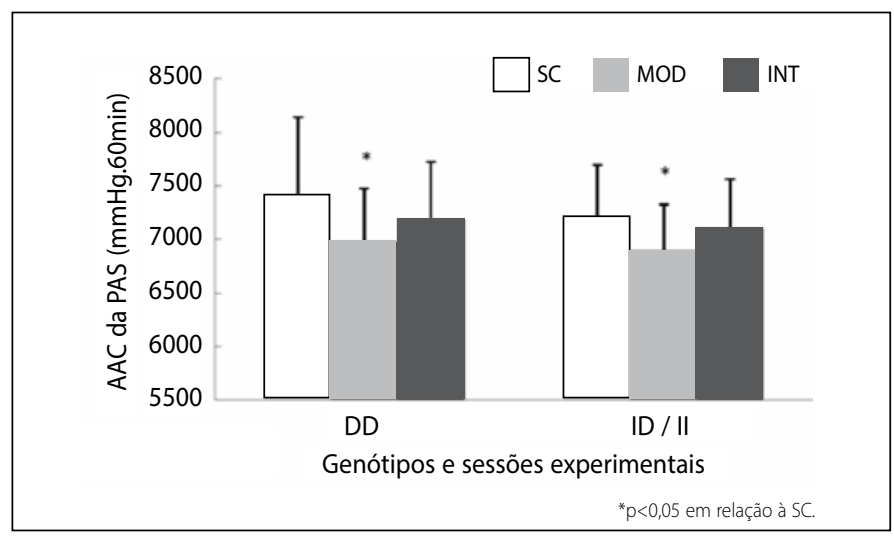

Figura 1. AAC da PAS durante o período após as sessões experimentais para cada grupo genotípico. 
Quanto à influência da característica genotípica dos voluntários, do protocolo de sessão experimental realizado, e da interação destas duas sobre a magnitude de decaimento da PAD após o exercício, verificou-se significativa influência da característica genotípica sobre a AAC pressórica da PAD (tabela 4 e figura 2).

Tabela 3. Valores absolutos de PAD (em mmHg) durante as três sessões experimentais de cada grupo genotípico, para a análise de HPE intra-grupos genotípicos.

\begin{tabular}{c|c|c|c|c|c|c}
\hline \multirow{2}{*}{ Testes } & \multirow{2}{*}{ Grupos } & \multirow{2}{*}{$\begin{array}{c}\text { Repouso } \\
\text { Pré }\end{array}$} & \multicolumn{4}{|c}{ Pós-exercício } \\
\cline { 4 - 7 } & & & $\operatorname{Rec} 15$ & $\operatorname{Rec} 30$ & $\operatorname{Rec} 45$ & $\operatorname{Rec} 60$ \\
\hline \multirow{2}{*}{ SC } & $\mathrm{DD}$ & $73,6 \pm 0,9$ & $77,7 \pm 8,9$ & $75,5 \pm 10,4$ & $76,1 \pm 10,0$ & $78,9 \pm 7,9$ \\
\cline { 4 - 7 } & $\mathrm{ID} / \|$ & $70,8 \pm 1,3$ & $73,4 \pm 9,9$ & $71,5 \pm 9,3$ & $72,9 \pm 9,2$ & $73,5 \pm 9,4$ \\
\hline \multirow{2}{*}{ MOD } & $\mathrm{DD}$ & $71,9 \pm 1,1$ & $75,8^{*} \pm 7,6$ & $70,7^{*} \pm 8,2$ & $69,8 \pm 7,2$ & $70,5 \pm 8,9$ \\
\cline { 4 - 7 } & $\mathrm{ID} / \|$ & $71,6 \pm 2,1$ & $72,2 \pm 8,5$ & $69,4 \pm 7,8$ & $69,7 \pm 7,4$ & $67,5^{*} \pm 8,9$ \\
\hline \multirow{2}{*}{ INT } & $\mathrm{DD}$ & $71,9 \pm 1,1$ & $75,8 \pm 7,6$ & $70,7 \pm 8,2$ & $69,8 \pm 7,2$ & $70,5 \pm 8,9$ \\
\cline { 4 - 7 } & $\mathrm{ID} / \|$ & $72,5 \pm 1,2$ & $73,7 \pm 7,7$ & $71,2 \pm 9,2$ & $71,9 \pm 8,1$ & $70,8 \pm 10,4$ \\
\hline
\end{tabular}

${ }^{*} p \leq 0,05$ em relação ao repouso pré-exercício.

Tabela 4. Influência das características genotípicas, das sessões experimentais e da interação destas sobre a AAC da PAD.

\begin{tabular}{c|c|c}
\hline Variáveis & Valor de $\mathbf{F}$ & Significância \\
\hline Genótipos & 8,335 & 0,005 \\
\hline Sessões experimentais & 0,979 & 0,381 \\
\hline Genótipos x sessões experimentais & 0,557 & 0,576 \\
\hline
\end{tabular}

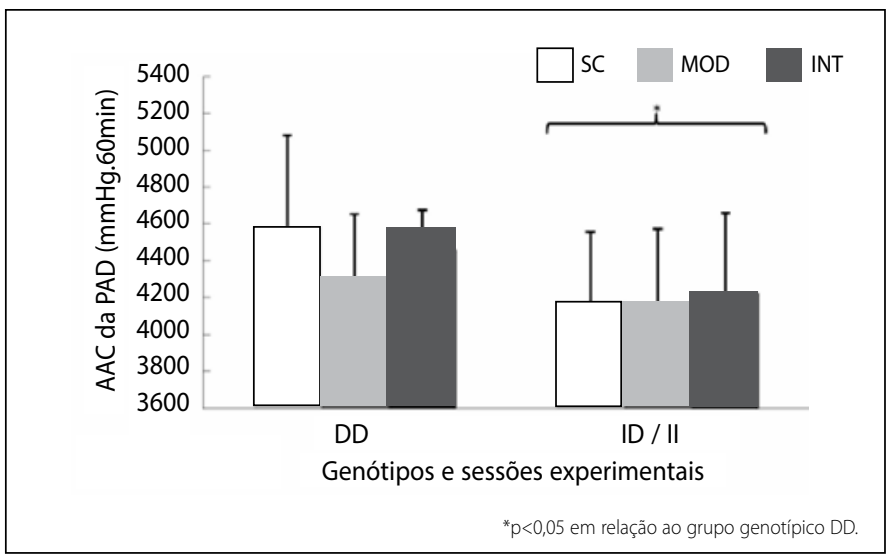

Figura 2. AAC da PAD durante o período após as sessões experimentais para cada grupo genotípico.

\section{DISCUSSÃO}

Os principais achados do presente estudo foram a ocorrência da HPE mais evidenciada para a PAS após a sessão MOD, independentemente do grupo genotípico (Tabela 1), havendo diferença da AAC da PAS após a sessão MOD em relação à SC (Tabela 2 e Figura 1). Complementarmente, cabe ressaltar que as características genotípicas dos voluntários influenciaram a AAC após o exercício para a PAD (Tabela 4 e Figura 2).

Com o intuito de verificar a influência da intensidade do exercício sobre a HPE, foram adotadas uma sessão moderada (MOD: 6\% abaixo do limiar anaeróbio) e outra sessão intensa (INT: 6\% acima do limiar anaeróbio), ambas com o mesmo volume de exercício (20 min de corrida). A intensidade MOD proporcionou momentos de HPE, principalmente para a PAS, independentemente do grupo genotípico investigado. Este resultado corrobora os achados de Lizardo et al. ${ }^{19}$, contudo, estes autores verificaram que não apenas a sessão submáxima, mas também a máxima proporcionaram hipotensão sistólica. Já Pardono ${ }^{8}$ e Pardono et al. ${ }^{28}$ verificaram HPE tanto para a PAS, quanto para a PAD, após sessões de corrida máxima e submáxima em jovens normotensos e fisicamente ativos.

Estudos realizados com hipertensos sedentários ${ }^{20,21}$ também observaram que, tanto os exercícios ligeiramente mais intensos (acima de $70 \%$ do $\mathrm{VO}_{2 \max }$ ), quanto os menos intensos ( $50 \%$ do $\mathrm{VO}_{2 \max }$ ), proporcionaram HPE durante o período de 24h pós-exercício, entretanto, ao analisar o período noturno e do sono, o exercício mais intenso promoveu reduções pressóricas de maior magnitude ${ }^{20}$. Todavia, MacDonald et al. ${ }^{22}$, ao estudarem dois protocolos submáximos (50 e $70 \%$ do $\mathrm{VO}_{2}$ pico), verificaram que a intensidade do exercício não alterou a magnitude da resposta hipotensora, contudo, possivelmente, ambas as intensidades encontravam-se dentro do domínio moderado de intensidade de exercício, ou seja, abaixo do limiar anaeróbio ${ }^{23}$, semelhante à sessão MOD adotada em nosso estudo.

A AAC da PAS (Figura 1) evidenciou diferença entre as sessões MOD e SC, independente do grupo genotípico, ou seja, uma maior resposta hipotensora após a sessão MOD, característica não observada em relação à ACC da PAS após a sessão INT (Tabela 2). Esta variação na resposta pressórica após as diferentes intensidades de exercício, observada no presente estudo, pode ter relação ao fato de que a amostra ter sido composta por jovens saudáveis e fisicamente ativos, uma vez que evidências na literatura científica relatam que a ocorrência da HPE apresenta menor consistência em jovens normotensos ${ }^{24,25}$. Contudo, esta característica amostral foi de suma importância para que pudéssemos investigar a influência gênica sobre a HPE, uma vez que estes voluntários ainda não foram tão expostos aos fatores ambientais, às alterações endoteliais deletérias relacionadas ao processo de envelhecimento e tampouco às fisiopatologias em geral, como a $\mathrm{HAS}^{8}$.

Pardono ${ }^{8}$ e Pardono et al. ${ }^{28}$ verificaram HPE após sessões máxima e submáxima, em jovens normotensos, sendo que Pardono ${ }^{8}$ também observou que os indivíduos carreadores do alelo "I", para o polimorfismo I/D no gene da ECA, obtiveram melhor resposta hipotensora quando comparados àqueles carreadores do alelo "D". Esta influência genética também foi evidenciada no presente estudo (Tabela 4), no qual a AAC da PAD pós-exercício sofreu influência da característica genotípica dos voluntários, sendo evidenciado melhor resposta hipotensora para os indivíduos carreadores do alelo "I" (Figura 2).

Complementarmente, Blanchard et al. ${ }^{26}$ investigaram a relação entre a interação de três polimorfismos do SRAA com a PA durante 14 horas após a realização de exercícios de baixa e moderada intensidades em adultos normotensos limítrofes e hipertensos (estágio 1), encontrando diferença entre os valores pressóricos pós-exercício dos grupos DD e II/ID. Ainda, Pescatello et al..$^{12}$ relataram que a resposta pressórica após exercício aeróbico, encontrada em seu estudo, possa ter sido modulada pelas interações entre ingestão dietética de cálcio, intensidade do exercício e polimorfismos no SRAA.

Segundo Tanriverdi et al. ${ }^{27}$, o alelo D associa-se à concentrações mais elevadas de ECA na circulação e nos tecidos, favorecendo a vasoconstrição. Ademais, estes autores observaram que a vasodilatação endotélio-dependente encontrava-se aumentada nos atletas de endurance que apresentavam o genótipo II da ECA. Por fim, de acordo com Santana et al. ${ }^{13}$, idosas carreadoras do alelo "I" obtiveram maior HPE e maior biodisponibilidade de óxido nítrico, ou seja, maior capacidade vasodilatadora do endotélio.

De maneira geral, embora alguns estudos demonstrem que a HPE tende a não ocorrer ou a ocorrer em menor magnitude em jovens normotensos ${ }^{24,25}$, Whelton et al. ${ }^{2}$ ressaltam que reduções pressóricas de 3 a $5 \mathrm{mmHg}$ são suficientes para diminuir de 4 a $7 \%$ o risco de 
mortalidade geral causada por doenças cardiovasculares, sendo que uma redução de $2 \mathrm{mmHg}$ da PAD está associada a uma redução de 17\% na prevalência de HAS na população em geral. Logo, exercitar-se, preferencialmente sob orientação, resultará em constantes HPE (ou mesmo pequenas reduções pressóricas pós-exercício) ao longo dos anos, independentemente de sua característica genotípica, favorecendo a manutenção de um status cardiovascular mais "saudável" e com menor suscetibilidade a doenças cardiovasculares.

Embora não invalide os resultados obtidos, entendemos que o presente estudo apresenta enquanto limitação o método indireto de determinação do limiar anaeróbio para a realização das sessões de exercício e obtenção da HPE. Recomendam-se métodos diretos de determinação desta intensidade, uma vez que os métodos indiretos podem superestimar ou subestimar a posterior prescrição dos exercícios.

\section{CONCLUSÃO}

Conclui-se que o exercício moderado proporciona HPE em jovens normotensos e fisicamente ativos, independente do polimorfismo I/D no gene da ECA. Ademais, este polimorfismo influencia a HPE para a PAD, ou seja, indivíduos carregadores do alelo "I" apresentam maior decaimento da PAD.

\section{AGRADECIMENTOS}

Os autores agradecem a Coordenação de Aperfeiçoamento de Pessoal de Nível Superior (CAPES) pelo apoio dado a esta pesquisa.

Todos os autores declararam não haver qualquer potencial conflito de interesses referente a este artigo.

\section{REFERÊNCIAS}

1. Pescatello LS, Franklin BA, Fagard R, Farquhar WB, Kelley GA, Ray CA, et al. American College of Sports Medicine position stand. Exercise and hypertension. Med Sci Sports Exerc. 2004;36(3):533-53.

2. Whelton PK, He J, Appel L, Cutler JA, Havas S, Kotchen TA, et al. Primary prevention of hypertension: clinical and public health advisory from The National High Blood Pressure Education Program. JAMA. 2002;288(15):1882-8.

3. Cornelissen VA, Fagard RH. Effects of endurance training on blood pressure, blood pressure-regulating mechanisms, and cardiovascular risk factors. Hypertension. 2005;46(4):667-75.

4. Mota MR, Oliveira RJ, Terra DF, Pardono E, Dutra MT, de Almeida JA, et al. Acute and chronic effects of resistance exercise on blood pressure in elderly women and the possible influence of ACE I/D polymorphism. Int J Gen Med. 2013;6:581-7.

5. Kenney MJ, Seals DR. Postexercise hypotension. Key features, mechanisms, and clinical significance. Hypertension. 1993;22(5):653-64

6. MacDonald JR. Potential causes, mechanisms, and implications of post exercise hypotension. J Hum Hypertens. 2002;16(4):225-36

7. Pardono $E$, Almeida MB, Bastos $A A$, Simões HG. Hipotensão pós-exercício: possível relação com fatores étnicos e genéticos. Rev Bras Cineantropom Desempenho Hum. 2012;14:353-61.

8. Pardono E. Influência do polimorfismo I/D do gene da enzima conversora de angiotensina sobre a hipotensão pós-exercício de jovens normotensos [tese]. Brasília: Universidade Católica de Brasília; 2010.

9. Ward R. Familial aggregation and genetic epidemiology of blood pressure. Título do capítulo. In: Hypertension: patholophysiology, diagnosis and management. Laragh JH, Brenner BM, editors. New York: Raven Press; 1990. p. 67-88.

10. Bleumink GS, Schut AF, Sturkenboom MC, van Duijn CM, Deckers JW, Hofman A, et al. Mortality in patients with hypertension on angiotensin-I converting enzyme (ACE)-inhibitor treatment is influenced by the ACE insertion/deletion polymorphism. Pharmacogenet Genomics. 2005;15(2):75-81.

11. Montgomery HE, Clarkson P, Dollery CM, Prasad K, Losi MA, Hemingway H, et al. Association of angiotensin-converting enzyme gene I/D polymorphism with change in left ventricular mass in response to physical training. Circulation. 1997;96(3):741-7.

12. Pescatello LS, Turner D, Rodriguez N, Blanchard BE, Tsongalis GJ, Maresh CM, et al. Dietary calcium intake and renin angiotensin system polymorphisms alter the blood pressure response to aerobic exercise: a randomized control design. Nutr Metab (Lond). 2007;4:1.

13. Santana HA, Moreira SR, Neto WB, Silva CB, Sales MM, Oliveira VN, et al. The higher exercise intensity and the presence of allele I of ACE gene elicit a higher post-exercise blood pressure reduction and nitric oxide release in elderly women: an experimental study. BMC Cardiovasc Disord. 2011;11:71.

14. Sotero Rda C, Pardono E, Campbell CS, Simões HG. Indirect assessment of lactate minimum and maximal blood lactate steady-state intensity for physically active individuals. J Strength Cond Res. 2009;23(3):847-53.

15. Cuckson AC, Reinders A, Shabeeh H, Shennan AH, British Hypertension Society. Validation of the Microlife BP 3BTO-A oscillometric blood pressure monitoring device according to a modified British Hypertension Society protocol. Blood Press Monit. 2002;7(6):319-24.

16. Leite TKM. Associação entre o polimorfismo I/D no gene da enzima conversora de angiotensina e a potencia aeróbia em idosas brasileiras [tese]. Brasília: Universidade Católica de Brasilia; 2008.

17. Shanmugam V, Sell KW, Saha BK. Mistyping ACE heterozygotes. PCR Methods Appl. 1993;3(2):120-1.

18. González AJ, Hernández D, DeVera A, Barrios Y, Salido E, Torres A, Terrados N. ACE gene polymorphism and erythropoietin in endurance athletes at moderate altitude. Med Sci Sports Exerc. 2006;38(4):688-93.

19. Lizardo JHF, Modesto LK, Campbell CSG, Simões HG. Hipotensão pós-exercício: comparação entre diferentes intensidades de exercício em esteira ergométrica e cicloergômetro. Rev Bras Cineantropom Desempenho Hum. 2007;9(2):115-20.

20. Quinn TJ. Twenty-four hour, ambulatory blood pressure responses following acute exercise: impact of exercise intensity. J Hum Hypertens. 2000;14(9):547-53.

21. Marceau M, Kouamé $N$, Lacourcière $Y$, Cléroux J. Effects of different training intensities on 24-hou blood pressure in hypertensive subjects. Circulation. 1993;88(6):2803-11.

22. MacDonald JR, MacDougall JD, Interisano SA, Smith KM, McCartney N, Moroz JS, et al. Hypotension following mild bouts of resistance exercise and submaximal dynamic exercise. Eur J Appl Physiol Occup Physiol. 1999;79(2):148-54.

23. Simões HG, Denadai BS, Baldissera V, Campbell CS, Hill DW. Relationships and significance of lactate minimum, critical velocity, heart rate deflection and $3000 \mathrm{~m}$ track-tests for running. J Sports Med Phys Fitness. 2005;45(4):441-51.

24. Pescatello LS, Miller B, Danias PG, Werner M, Hess M, Baker C, et al. Dynamic exercise normalizes resting blood pressure in mildly hypertensive premenopausal women. Am Heart J. 1999;138(5 Pt 1):916-21.

25. Wallace JP, Bogle PG, King BA, Krasnoff JB, Jastremski CA. The magnitude and duration of ambulatory blood pressure reduction following acute exercise. J Hum Hypertens. 1999;13(6):361-6.

26. Blanchard BE, Tsongalis GJ, Guidry MA, LaBelle LA, Poulin M, Taylor AL, et al. RAAS polymorphisms alter the acute blood pressure response to aerobic exercise among men with hypertension. Eur $\rfloor$ Appl Physiol. 2006;97(1):26-33.

27. Tanriverdi $\mathrm{H}$, Evrengul H, Tanriverdi S, Turgut S, Akdag B, Kaftan HA, et al. Improved endothelium dependent vasodilation in endurance athletes and its relation with ACE I/D polymorphism. Circ J. 2005;69(9):1105-10

28. Pardono E, Fernandes MO, Azevêdo LM, Almeida JA, Mota MR, Simões HG. Post-exercise hypotension of normotensive young men through track running sessions. Rev bras med esporte. 2015;21(3):192-195. 